\title{
Sevoflurane consumption using automatic gas control versus manual gas control with Flow-I: comparative consumption in 200 patients
}

De Rydt F, Goossens J, Allaert S, Kalmar AF

Maria Middelares Hospital, Dept of Anesthesia \& Critical Care, Gent, Belgium

\section{Background and Goal}

Traditionally, sevoflurane delivery was performed in high fresh gas flow (FGF), mainly owing to two reasons: 1-lack of precise monitoring of gas concentrations, and 2-ease of reliable administration. Being a recognised greenhouse gas with a considerable price tag, cutting down the waste of volatile anaesthetics promises important ecologic and economic benefits. Automated gas control(AGC) of the Flow-I ventilator(Maquet) permits easy and reliable administration of volatiles with minimal operator intervention, while significantly decreasing waste. Still, manual gas (MGC) with swift decrease of FGF may permit further waste reduction, albeit with significantly more manual interventions. The aim of the present study was to compare sevoflurane consumption in AGC versus low-flow MGC.

\section{Materials and Methods}

In this study, either AGC or MGC was used in $2 \times 100$ consecutive patients. All patients were anesthetized by the same clinician. Volatile administration was initiated after induction of anesthesia (with propofol), intubation and start of mechanical ventilation. In both groups 1 MAC was pursued: in the first group, AGC mode (speed 6) was used, in the second group using MGC, sevoflurane concentration in fresh gas was set at $8 \%$, with high FGF for 3 ventilations, and
Subsequent adjusted to a minimal FGF of $0.3 \mathrm{ml} / \mathrm{min}$ with ensuing single-breaths of high FGF if necessary.

\section{Results and Discussion}

Individual and Mean(SD) anesthesia time and sevoflurane consumption in both groups are shown in figure 1 . Linear regression analysis shows a consumption of $0.141 \mathrm{ml} / \mathrm{min}$ in the AGC group and $0.095 \mathrm{ml} / \mathrm{min}$ in the MGC group. The simulated sevoflurane consumption with constant flow sevoflurane administration is $0.213 \mathrm{ml} / \mathrm{min}$ in 2L FGF and $0.639 \mathrm{ml} / \mathrm{min}$ in $6 \mathrm{~L}$ FGF.

\section{Conclusion}

AGC significantly reduces the usage of agent compared to traditional constant FGF setting. Our results, however, clearly indicate that the current AGC-algorithms still have substantial room for improvement, since manual gas control with minimal flow anesthesia still results in a $33 \%$ lower consumption.

\section{References}

1. Biro P. Acta Anaesthesiol Scand. 2014;58:968-72.

\section{Sevoflurane consumption in}

\section{Manual vs Automatic Gas Control}

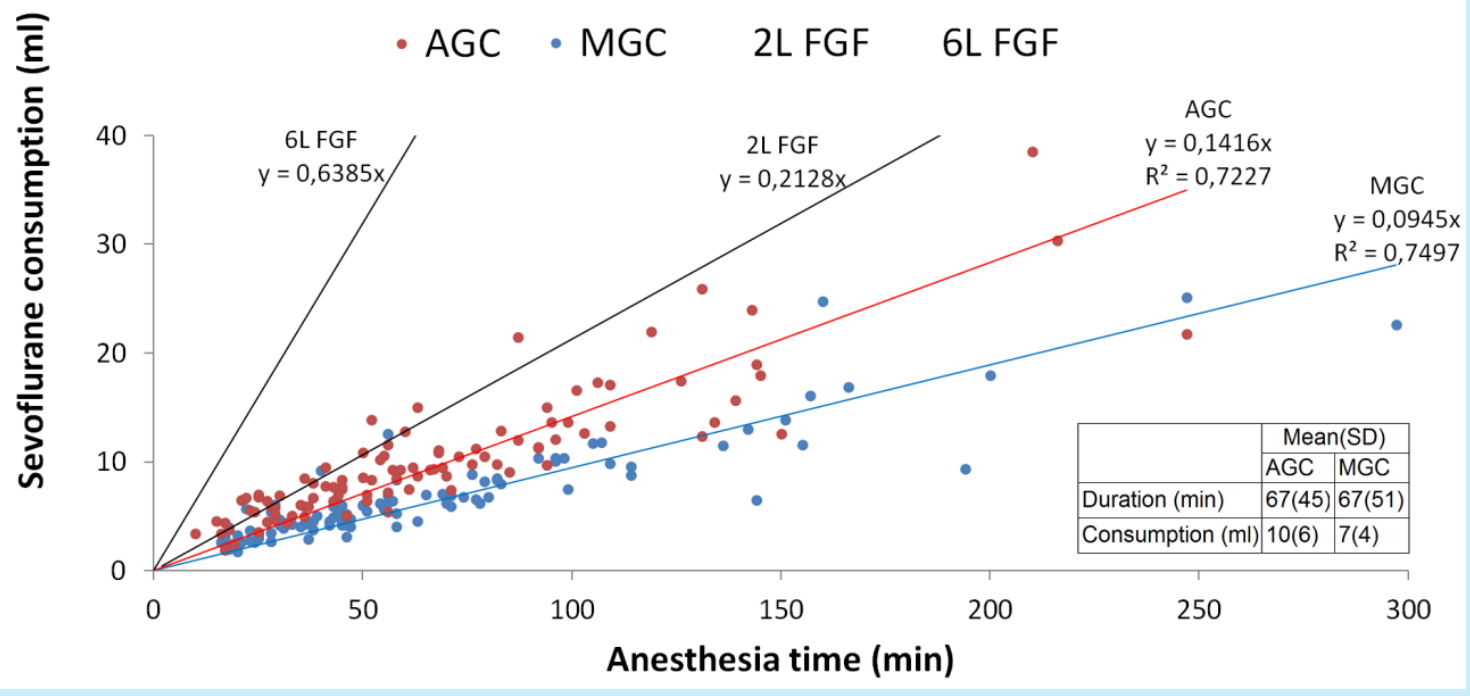

